\title{
Correlações entre viabilidade de pólen e características de frutos em mutantes de laranjeira 'Pêra'
}

\author{
Rodrigo Rocha Latado(1), Julio Silvio Sousa Bueno Filho(2), Jorgino Pompeu Junior(3) e Augusto Tulmann Neto(1)
}

(1)Universidade de São Paulo (USP), Centro de Energia Nuclear na Agricultura (Cena), Laboratório de Melhoramento de Plantas, Av. Centenário, 303, CEP 13400-970 Piracicaba, SP. E-mail: rrlatado@cena.usp.br, tulmann@cena.usp.br (2)Universidade Federal de Lavras, Dep. de Ciências Exatas, Caixa Postal 37, CEP 37200-000 Lavras, MG. E-mail: jssbueno@ufla.br (3) Centro APTA Citros, Rod. Anhanguera, Km 158, s/no, Caixa Postal 04, CEP 13490-970 Cordeirópolis, SP. E-mail: jorgino@centrodecitricultura.br

\begin{abstract}
Resumo - O objetivo deste trabalho foi avaliar, durante dois anos, a viabilidade de grãos de pólen e as correlações entre essa viabilidade e as características de frutos de plantas mutantes de laranjeira 'Pêra'. As plantas mutantes foram obtidas a partir de tratamento de borbulhas com raios-gama e selecionadas após três propagações vegetativas. A viabilidade dos grãos de pólen foi avaliada pelo método de coloração com carmin acético. Não houve diferenças entre anos na viabilidade de grãos de pólen e no número de sementes por fruto, indicando que estes caracteres não foram afetados pelas alterações ambientais anuais. Correlações positivas e significativas foram observadas entre a viabilidade média dos grãos de pólen e o número médio de sementes por fruto e, também, com o teor de sólidos solúveis totais do suco dos frutos. Uma das razões para a existência de mutantes com menor número de sementes por fruto é a baixa porcentagem de grãos de pólen viáveis.
\end{abstract}

Termos para indexação: Citrus sinensis, suco, mutação, sementes.

\section{Correlations between pollen grain viability and fruit characteristics in 'Pêra' sweet orange mutants}

\begin{abstract}
The objective of this work was to evaluate the pollen grain viability of 'Pêra' sweet orange mutant plants and to estimate its correlation with fruit characteristics. Mutant plants were obtained from shoot treatment with gamma-rays and selected after three vegetative propagations. Pollen grain viability was evaluated using carmine-acetic staining method. No difference was found between years for pollen grain viability and for number of seeds per fruit, indicating that these characters were not affected by the yearly environmental alterations. Positive correlations were found between pollen grain viability and mean number of seeds per fruit, and with the total soluble solid content in juice. Therefore, one of the reasons for the smaller number of seeds per fruit in these mutants is the low percentage of viable pollen grain.
\end{abstract}

Index terms: Citrus sinensis, juice, mutation, seeds.

\section{Introdução}

Apesar de o Brasil ser o maior produtor mundial de laranjas e de suco cítrico, sua participação no comércio internacional de frutas cítricas para o consumo in natura é pequena. (Agrianual, 2002). Uma das principais razões é a inexistência de variedades com frutos sem sementes e com características adequadas para a exportação (Pio, 1993).

A laranjeira 'Pêra' (Citrus sinensis (L.) Osbeck) é a principal variedade cultivada no Estado de São Paulo, com $37,8 \%$ do total, sendo utilizada tanto no processamento de suco como no mercado de frutas frescas (Pompeu Junior, 2001).
Em citros, a ausência ou o baixo número de sementes podem ser causados pela esterilidade feminina, autoincompatibilidade e partenocarpia (Yamamoto \& Tominaga, 2002), incompatibilidade com pólen de outras variedades (Wallace \& Lee, 1999), esterilidade masculina, causada pela existência de flores com anteras abortadas (Yamamoto et al., 1992, 1993), baixa produção de grãos de pólen nas anteras (Yamamoto et al., 1992, 1993) e por flores contendo pólen com baixa viabilidade (Moreira \& Gurgel, 1941).

A influência da fonte de pólen em caracteres relevantes relacionados à produção e à qualidade de frutos cítricos já foi comprovada, principalmente na taxa de pegamento de frutos, no peso de frutos, no número de 
sementes por fruto, na acidez e no conteúdo total de açúcares do suco (Vithanage, 1991; Wallace \& Lee, 1999). Esta influência mostra-se mais pronunciada em variedades auto-incompatíveis.

Latado et al. (2001) selecionaram, entre 127 clones mutantes de laranjeira 'Pêra', nove clones com frutos sem sementes (menos de uma semente por fruto) e 15 outros com frutos contendo baixo número de sementes (entre uma e duas sementes por fruto), obtidos a partir de mutagênese induzida com raios-gama.

O objetivo deste trabalho foi avaliar, durante dois anos, correlações entre a viabilidade de grãos de pólen e algumas características de fruto, em mutantes de laranjeira 'Pêra'.

\section{Material e Métodos}

Um total de 121 clones mutantes de laranjeira 'Pêra IAC', pré-imunizada contra o vírus-da-tristeza dos citros, foi selecionado numa população de plantas obtidas a partir de borbulhas irradiadas com 40 Gy de raios-gama, seguido de três propagações vegetativas (Tulmann Neto et al., 1996). Esses clones mutantes apresentaram uma ou mais características distintas do material inicial, tais como menor porte, frutos com menor número ou ausência de sementes, frutos maiores ou menores, frutos com maturação precoce ou tardia e plantas com alta produtividade.

O pomar contendo esses clones foi instalado em 1993, na Estação Experimental do Instituto Biológico do Estado de São Paulo, em Presidente Prudente. O espaçamento de plantio foi de $4,0 \times 7,0 \mathrm{~m}$, perfazendo quatro hectares, sem irrigação. Foram avaliadas 129 plantas, compreendendo os 121 clones mutantes e oito plantas-controle obtidas da planta original não-irradiada. Todas as plantas foram enxertadas sobre limoeiro 'Cravo' $(C$. limonia Osb.).

Dez botões florais, em estádio de desenvolvimento máximo e antes da antese, foram coletados de cada planta e mantidos em placas de Petri durante 24 horas, até a abertura das anteras, as quais foram coletadas com auxílio de pinça, transferidas para tubos de plástico contendo 0,5 mL de solução 3:1 (álcool absoluto:ácido acético glacial) e armazenadas a $4^{\circ} \mathrm{C}$, até o momento das análises.

A viabilidade de pólen foi avaliada por meio da coloração com carmin acético a 2,5\% sobre lâminas de vidro, seguida de observação em microscópio ótico (Domingues et al., 2000). Os grãos viáveis apresenta- vam-se circulares, com superfície uniforme e coloração vermelho-intenso, enquanto os grãos inviáveis apresentavam menor tamanho, superfície irregular, formato nãouniforme e coloração amarelo-claro.

Os experimentos foram realizados nos anos de 1999 e 2000. Em cada ano, anotou-se a porcentagem de grãos de pólen viáveis de cada tratamento, em três observações, e calcularam-se a média de cada tratamento e a porcentagem média de grãos de pólen viáveis.

Os frutos resultantes de polinização livre foram avaliados mediante a coleta de amostras de frutos ao acaso, de cada tratamento (planta), nos anos 2000 e 2001. Mediram-se a altura e a largura de dez frutos e calcularam-se a altura e a largura média do fruto de cada tratamento em cada ano e a média dos dois anos. Os frutos foram então pesados, calculando-se o peso médio de frutos de cada tratamento em cada ano e a média dos dois anos.

O suco dos dez frutos de cada tratamento foi extraído e homogeneizado. Retirou-se uma amostra de $200 \mathrm{~mL}$ para análise de suas características. Os teores de sólidos solúveis totais (SST) foram determinados em refratômetro e os valores expressos em graus Brix. A acidez total foi determinada por meio de titulação, de acordo com Latado et al. (2001). O ratio (relação acidez:sólidos solúveis) foi calculado por meio da razão entre o SST e a acidez total titulável da amostra. Utilizaram-se os dados obtidos em dois anos para o cálculo do teor médio de sólidos solúveis, da acidez média do suco e do ratio médio.

As sementes dos dez frutos foram contadas, calculando-se o número médio de sementes por fruto dos tratamentos em cada ano e a média obtida nos dois anos de avaliação.

Os dados de porcentagem de grãos de pólen viáveis foram submetidos à transformação arco seno da raiz quadrada da porcentagem observada, de forma a se estabilizar a variância residual entre os clones.

Foram feitas análises de variância preliminares conforme o modelo: $y_{i j k}=m+a_{i}+c_{j}+(a c)_{i j}+e_{i j k}$, em que $\mathrm{y}_{\mathrm{ijk}}$ corresponde a cada um dos caracteres observados na k-ésima repetição do clone i no ano j; m é uma constante experimental; $a_{i}$ são os efeitos dos anos $i ; c_{j}$ são os efeitos dos clones j; (ac) ij $_{\mathrm{ij}}$ são os efeitos das interações entre os clones i e os anos j; e e $\mathrm{e}_{\mathrm{ijk}}$ é o erro experimental.

Em seguida foram calculadas e testadas correlações de Pearson para medir a associação entre os diversos caracteres que apresentaram variabilidade: porcentagem 
de grãos de pólen com número médio de sementes por fruto, tamanho e peso médio de frutos, teor de sólidos solúveis totais (SST), acidez média e ratio médio do suco.

\section{Resultados e Discussão}

A porcentagem média de grãos de pólen viáveis nos clones mutantes variou entre $8,1 \%$ a $68,9 \%$, e foi considerada alta, já que esses mutantes foram obtidos a partir do tratamento mutagênico de apenas um material original (controle), cuja viabilidade média de pólen foi de $51,7 \%$ (Tabela 1). Por meio do teste F, detectou-se que as diferenças na viabilidade de pólen dos diversos tratamentos foram significativas.

Esta alta variação na porcentagem de grãos de pólen viáveis pode ser creditada à ocorrência de mutações em plantas, o que resultou na produção de mutantes com

Tabela 1. Número de sementes por fruto e viabilidade de pólen de alguns clones mutantes de laranjeira 'Pêra' (Citrus sinensis (L.) Osbeck) e do controle ${ }^{(1)}$.

\begin{tabular}{|c|c|c|}
\hline $\begin{array}{l}\text { Clones } \\
\text { mutantes }\end{array}$ & $\begin{array}{l}\text { Número de sementes } \\
\text { por fruto }\end{array}$ & $\begin{array}{l}\text { Viabilidade de pólen } \\
(\%)\end{array}$ \\
\hline 58 & 0,2 & 8,1 \\
\hline 16 & 0,2 & 21,7 \\
\hline 59 & 0,2 & 20,1 \\
\hline 27 & 0,3 & 17,6 \\
\hline 21 & 0,3 & 28,5 \\
\hline 33 & 0,4 & 54,2 \\
\hline 101 & 0,5 & 22,5 \\
\hline 28 & 0,6 & 29,0 \\
\hline 71 & 0,6 & 30,2 \\
\hline 6 & 0,7 & 27,0 \\
\hline 78 & 0,8 & 16,6 \\
\hline 41 & 0,8 & 15,4 \\
\hline 32 & 1,0 & 39,4 \\
\hline 46 & 1,0 & 55,5 \\
\hline 42 & 1,1 & 31,8 \\
\hline 57 & 1,1 & 16,3 \\
\hline 13 & 1,2 & 18,1 \\
\hline 110 & 6,4 & 59,5 \\
\hline 35 & 6,7 & 58,3 \\
\hline 44 & 6,8 & 63,1 \\
\hline 133 & 6,9 & 61,8 \\
\hline 61 & 6,9 & 52,1 \\
\hline 63 & 7,4 & 57,6 \\
\hline 11 & 7,6 & 56,8 \\
\hline 73 & 8,2 & 68,9 \\
\hline Controle & 5,3 & 51,7 \\
\hline $\mathrm{F}$ & $4,3^{* *}$ & $4,0 * *$ \\
\hline $\mathrm{CV}(\%)$ & 21,1 & 35,7 \\
\hline
\end{tabular}

${ }^{(1)}$ Médias de dez frutos de cada planta, compreendendo 32 plantas do controle e quatro plantas de cada clone mutante, durante dois anos consecutivos. ${ }^{*}$ Significativo a $1 \%$ de probabilidade. flores contendo pólen com baixa viabilidade. De acordo com Moreira \& Gurgel (1941), em citros, a variação encontrada na viabilidade de pólen entre plantas de uma mesma variedade e de origem única é geralmente pequena.

No entanto, a viabilidade de pólen pode variar mais quando se comparam distintas variedades de citros. Moreira \& Gurgel (1941) encontraram, em laranjeiras doces, viabilidade de pólen entre $0 \%$ e $90 \%$, enquanto Domingues et al. (2000) encontraram valores entre $28,1 \%$ e $57,3 \%$, na avaliação de diversos clones de laranjeira 'Pêra'.

Com relação ao número de sementes por fruto, observou-se também uma alta variação entre os mutantes, com médias entre 0,2 e 8,2 sementes por fruto, enquanto o controle apresentou frutos com média de 5,3 sementes, nos dois anos consecutivos do experimento (Tabela 1). Essa variação é também atribuída à presença de mutantes induzidos que produziram frutos com baixo número de sementes.

Não foi observada a existência de diferenças entre os anos na viabilidade de grãos de pólen e no número de sementes por fruto, indicando que esses caracteres não foram afetados pelas variações ambientais anuais.

Uma correlação positiva e altamente significativa foi encontrada entre a viabilidade média dos grãos de pólen e o número médio de sementes por fruto nas plantas avaliadas (Tabela 2). Os mutantes que apresentaram pólen com baixa viabilidade possuíam baixo número de sementes nos frutos, enquanto alta viabilidade de pólen mostrou-se associada a um alto número de sementes, com exceção dos clones 33 e 46, que apresentaram mediana viabilidade de pólen (acima de 50\%) e frutos contendo baixo número de sementes (Tabela 1).

Tabela 2. Correlação do número de sementes por fruto $\left(\mathrm{Y}_{1}\right)$, do peso médio $(\mathrm{g})$ de frutos $\left(\mathrm{Y}_{2}\right)$ e do teor de sólidos solúveis totais ( ${ }^{\circ}$ Brix) do suco de frutos $\left(\mathrm{Y}_{3}\right)$, com a viabilidade média de grãos de pólen $(\mathrm{X})$, de clones mutantes de laranjeira 'Pêra' (Citrus sinensis (L.) Osbeck) e do controle ${ }^{(1)}$.

\begin{tabular}{|c|c|}
\hline Equação de regressão & Coeficiente de correlação \\
\hline $\begin{array}{l}Y_{1}=0,17 X-3,36 \\
Y_{2}=0,62 X+161,22 \\
Y_{3}=0,03 X+9,39\end{array}$ & $\begin{array}{l}\mathrm{r}=0,76^{* *} \\
\mathrm{r}=0,22^{\mathrm{ns}} \\
\mathrm{r}=0,34^{* *}\end{array}$ \\
\hline
\end{tabular}

Pesq. agropec. bras., Brasília, v.39, n.10, p.961-965, out. 2004 
No agrupamento de plantas pelo número médio de sementes por fruto, verificou-se que o grupo que apresentou frutos com maior número de sementes (acima de 4 sementes por fruto) associou-se a uma maior fertilidade de pólen (maior que 40\%). No grupo de plantas que se situaram na faixa de 0 a 2 sementes por fruto, observou-se uma alta variabilidade na porcentagem de grãos de pólen viáveis.

Moreira \& Gurgel (1941), avaliando diversas variedades de citros, encontraram resultados semelhantes, verificando uma correlação significativa, mas mediana, entre a viabilidade de grãos de pólen e o número de sementes por fruto (coeficiente de correlação $r=0,53$ ). Esses autores também observaram que as variedades com frutos contendo grande número de sementes, acima de 20, requeriam uma maior fertilidade de pólen. Já Yamamoto et al. (1993) observaram em progênies híbridas de citros que o número de sementes por fruto estava diretamente relacionado com a quantidade de pólen produzido nas flores.

Considerando que o presente estudo foi realizado em plantas com polinização aberta e que, segundo Domingues \& Tulmann Neto (1999), em laranjeiras doces a alogamia é predominante sobre a autogamia, devese considerar a possibilidade de, nas plantas mutantes, também ter havido uma redução na viabilidade dos óvulos proporcional à ocorrida nos grãos de pólen. Considerando-se a possibilidade da ocorrência de auto-incompatibilidade em plantas de laranja 'Pêra', relatada por Domingues \& Tulmann Neto (1999) em diferentes clones, poder-se-ia sugerir que a redução observada no número de sementes de alguns mutantes é decorrente da menor viabilidade de óvulos e não de grãos de pólen da planta. Estudos deverão ser realizados para a confirmação desta hipótese.

De forma semelhante ao verificado quanto ao número de sementes por fruto e quanto à viabilidade de pólen, observou-se também altas e significativas variações na altura, largura e peso de frutos de alguns clones (Tabela 3). Este fato comprova a ocorrência de mutações em plantas, resultando na obtenção de clones que produzem frutos maiores e em outros casos, a produção de frutos menores, sendo esta última considerada como indesejável para a utilização comercial.

Correlações positivas, porém não-significativas, foram observadas entre a viabilidade média dos grãos de pólen e os parâmetros peso médio de frutos, altura média e largura média de frutos (Tabela 2). Assim, o aumento da viabilidade média de grãos de pólen resultou em apenas um pequeno incremento no tamanho e no peso médio dos frutos e as plantas com flores contendo maior porcentagem de pólen viável não apresentaram frutos maiores e nem mais pesados.

Não foram observados mutantes que produziram frutos com características distintas das do controle, com relação aos parâmetros teor de sólidos solúveis totais (SST), acidez total e ratio, pois a análise de variância demonstrou não haver diferenças estatisticamente significativas entre os tratamentos (Tabela 4).

Tabela 3. Altura, largura e peso de frutos de alguns clones mutantes de laranjeira 'Pêra'(Citrus sinensis (L.) Osbeck) e do controle ${ }^{(1)}$.

\begin{tabular}{cccc}
\hline $\begin{array}{l}\text { Clones } \\
\text { mutantes }\end{array}$ & $\begin{array}{c}\text { Altura de fruto } \\
(\mathrm{cm})\end{array}$ & $\begin{array}{c}\text { Largura de } \\
\text { fruto }(\mathrm{cm})\end{array}$ & $\begin{array}{c}\text { Peso de fruto } \\
(\mathrm{g})\end{array}$ \\
\hline 13 & 5,8 & 5,9 & 110,0 \\
41 & 6,1 & 5,9 & 120,0 \\
64 & 6,5 & 6,2 & 135,0 \\
25 & 6,5 & 6,5 & 160,0 \\
57 & 6,6 & 6,1 & 132,5 \\
16 & 7,7 & 6,9 & 207,5 \\
71 & 7,7 & 7,6 & 237,5 \\
33 & 7,9 & 7,2 & 220,0 \\
10 & 8,0 & 7,5 & 250,0 \\
55 & 8,2 & 7,7 & 250,0 \\
\hline Controle & 7,1 & 6,7 & 176,1 \\
\hline F & $5,2 * *$ & $2,6^{*}$ & $3,0 * *$ \\
CV (\%) & 2,8 & 4,2 & 10,6 \\
\hline
\end{tabular}

${ }^{(1)}$ Médias de dez frutos de cada planta, compreendendo 32 plantas do controle e quatro plantas de cada clone mutante, durante dois anos consecutivos. $*$ e $* *$ Significativo a $5 \%$ e a $1 \%$ de probabilidade, respectivamente.

Tabela 4. Teor de sólidos solúveis totais ( $\left.{ }^{\circ} \mathrm{Brix}\right)$, acidez total e ratio (relação sólidos solúveis totais:acidez) do suco de frutos de alguns clones mutantes de laranjeira 'Pêra' (Citrus sinensis (L.) Osbeck) e do controle ${ }^{(1)}$.

\begin{tabular}{cccc}
\hline $\begin{array}{l}\text { Clones } \\
\text { mutantes }\end{array}$ & $\begin{array}{c}\text { Sólidos } \\
\text { solúveis totais }\end{array}$ & $\begin{array}{c}\text { Acidez } \\
\text { total }\end{array}$ & Ratio \\
\hline 16 & 9,5 & 0,4 & 21,6 \\
41 & 10,3 & 0,5 & 20,0 \\
6 & 9,6 & 0,5 & 19,1 \\
52 & 12,1 & 0,7 & 18,5 \\
21 & 8,8 & 0,6 & 15,1 \\
76 & 12,4 & 0,8 & 14,9 \\
56 & 11,0 & 1,0 & 11,5 \\
106 & 9,8 & 0,6 & 11,3 \\
28 & 9,9 & 0,9 & 11,0 \\
57 & 11,1 & 1,1 & 10,4 \\
\hline Controle & 10,6 & 0,7 & 14,9 \\
\hline F & $1,5^{\text {ns }}$ & $1,3^{\text {ns }}$ & $1,1^{\text {ns }}$ \\
CV (\%) & 7,8 & 19,8 & 16,2 \\
\hline
\end{tabular}

${ }^{(1)}$ Médias de dez frutos de cada planta, compreendendo 32 plantas do controle e quatro plantas de cada clone mutante, durante dois anos

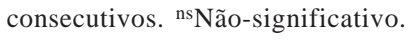


Encontrou-se uma correlação positiva significativa mas de magnitude mediana entre a viabilidade média dos grãos de pólen e o SST do suco dos frutos (Tabela 2). Já para as correlações da viabilidade do pólen, com acidez e com ratio, os coeficientes foram não-significati$\operatorname{vos}(r=0,03$, acidez; e $r=0,11$, ratio do suco).

Segundo Wallace \& Lee (1999), os efeitos de xenia, decorrentes da fonte de pólen, são mais pronunciados em variedades de citros auto-incompatíveis, mas podem também ser observados em autocompatíveis. Esses autores observaram efeitos de xenia no número de sementes por fruto, no conteúdo de açúcares do suco e no tamanho de frutos de tangerinas. Já no presente estudo, observou-se um elevado efeito de xenia no número de sementes por fruto e mediano efeito no teor de sólidos solúveis (SST) do suco.

\section{Conclusões}

1. As correlações da viabilidade média dos grãos de pólen com o número médio de sementes por fruto e com os teores de sólidos solúveis totais do suco de frutos de laranjeira 'Pêra' são positivas e significativas.

2. Não há correlação entre a viabilidade média dos grãos de pólen e caracteres de frutos de laranjeira 'Pêra' (altura, largura e peso) e do suco dos frutos (acidez e ratio).

\section{Agradecimentos}

À Fapesp, pelo apoio financeiro, nas formas de auxílio à pesquisa e bolsas de estudo.

\section{Referências}

AGRIANUAL: Anuário Estatístico da Agricultura Brasileira. São Paulo: FNP Consultoria e Comércio, 2002. p.285-315.

DOMINGUES, E.T.; TULMANN NETO, A. Influência da polinização e da morfologia floral na frutificação de variedades de laranja-doce. Scientia Agricola, v.56, p.163-170, 1999.
DOMINGUES, E.T.; TULMANN NETO A.; TEÓFILO SOBRINHO, J. Viabilidade de pólen em clones de laranja Pêra e outras variedades assemelhadas. Ciência Rural, v.30, p.85-89, 2000.

LATADO, R.R.; TULMANN NETO, A.; ANDO, A.; IEMMA, A.F.; POMPEU JUNIOR, J.; FIGUEIREDO, J.O.; PIO, R.M.; MACHADO, M.A.; NAMEKATA, T.; CERAVOLO, L.; ROSSI, A.C. Mutantes de laranja 'Pêra' com número reduzido de sementes, obtidos através de mutações induzidas. Revista Brasileira de Fruticultura, v.23, p.339-344, 2001.

MOREIRA, S.; GURGEL, J.T. A fertilidade do pólen e sua correlação com o número de sementes, em espécies e formas do gênero Citrus. Bragantia, v.1, p.669-711, 1941.

PIO, R.M. Tangerinas para o verão. Laranja, v.14, p.539-549, 1993.

POMPEU JUNIOR, J. Rootstocks and scions in the citriculture of the São Paulo State. In: INTERNATIONAL CONGRESS OF CITRUS NURSERYMEN, 6., Ribeirão Preto, 2001. Proceedings. Ribeirão Preto: International Society of Citrus Nurserymen, 2001. p.75-82.

TULMANN NETO, A.; MENTEN, J.O.M.; ANDO, A.; POMPEU JUNIOR, J.; FIGUEIREDO, J.O.; CERAVOLO, L.; NAMEKATA, T.; ROSSI, A.C. Indução e seleção de mutantes em laranja 'Pêra' mediante o emprego da radiação gama. Pesquisa Agropecuária Brasileira, v.31, p.743-752, 1996.

VITHANAGE, V. Effect of different pollen parents on seediness and quality of 'Ellendale' tangor. Scientia Horticulturae, v.48, p.253-260, 1991.

WALLACE, H.M.; LEE, L.S. Pollen source, fruit set and xenia in mandarins. Journal of Horticultural Science \& Biotechnology, v.74, p.82-86, 1999.

YAMAMOTO, M.; OKUDAI, N.; MATSUMOTO, R. Study on the inheritance of aborted anthers in citrus using seed parents having aborted anthers. Journal of the Japanese Society for Horticultural Science, v.60, p.791-797, 1992.

YAMAMOTO, M.; OKUDAI, N.; MATSUMOTO, R.; YAMADA, Y. Seed number of hybrid plants in citrus, with special reference to seed number of parents and pollen yield of individuals. Journal of the Japanese Society for Horticultural Science, v.61, p.757-762, 1993.

YAMAMOTO, M.; TOMINAGA, S. Relationship between seedlessness of Keraji (Citrus keraji Hort. ex Tanaka) and female sterility and self-incompatibility. Journal of the Japanese Society for Horticultural Science, v.71, p.183-186, 2002. 